\title{
Progress and challenges with clinical cell therapy in neurorestoratology
}

\author{
This article was published in the following Dove Press journal: \\ Journal of Neurorestoratology \\ 13 April 2015 \\ Number of times this article has been viewed
}

\author{
Hongyun Huang ${ }^{1-3}$ \\ Gengsheng Mao' \\ Lin Chen ${ }^{4,5}$ \\ Aibing Liu'
}

'General Hospital of Chinese People's Armed Police Forces, ${ }^{2}$ Beijing Rehabilitation Hospital of Capital Medical University, ${ }^{3}$ Beijing Hongtianji Neuroscience Academy, ${ }^{4} \mathrm{~T}$ singhua University Yuquan Hospital, ${ }^{5}$ Medical Center, Tsinghua University, Beijing, People's Republic of China
Correspondence: Hongyun Huang No. 69 Yongding Road, Institute of Neurorestoratology, General Hospital of Armed Police Force, Beijing 100939, People's Republic of China

Tel +86 I39I0II6608

Email hongyunh@gmail.com
Abstract: Cell therapies in the treatment of central nervous system disease and injury, such as spinal cord injury, multiple sclerosis, sequelae of stroke, amyotrophic lateral sclerosis, and cerebral palsy, have been studied in the clinic for the last 10-20 years. Excitingly, many studies have demonstrated that most patients appear to have some functional improvement following administration of different types of cells by different routes with relatively low risk and good tolerability. However, there are some misconceptions that hinder the development of cell-based neurorestorative strategies. It is a considerable challenge but also an opportunity for physicians in neurorestoratology to face these issues. This review briefly outlines the progress made in neurorestoratology, discusses the relevant issues, and attempts to correct the misconceptions. Keywords: neurorestorative strategies, cell therapy, progress, challenges, neurorestoratology

\section{Introduction}

Over 30 different types of cells have been studied in basic neurorestoration research and have been shown to be safe and effective in improving neurological function. ${ }^{1,2}$ Many studies have focused on the mechanisms of functional restoration by cell therapies, including neuromodulation or unmasking and signaling repair by changing the microenvironment, neuroprotection by neurotrophins and immune or inflammatory modulation, neuroplasticity or neural circuit, network reconstruction and neurosynapsis, axonal remyelination or neurorepair, axon sprouting and regeneration, neuroreplacement, neurogenesis, and angiogenesis. ${ }^{1-3}$ With developments in this field, some misunderstandings have arisen and had a detrimental effect on the development of neurorestoratology. ${ }^{3}$ To correct these misconceptions is a challenge. This review briefly summarizes the clinical progress made in neurorestoratology and the ongoing challenges associated with cell therapy.

\section{Classification of cells applied clinically}

Cells as a tool for neurorestorative strategies can be classified into three types:

- Immature or mature functional cells, including neural progenitor or precursor cells, olfactory ensheathing cells, Schwann cells, and neurons

- Mesenchymal or stromal cells, including bone marrow, umbilical cord or peripheral blood mononuclear or stromal cells, umbilical cord stromal cells, and adipose stromal cells

- Totipotent or pluripotent stem cells, including embryonic stem cell or induced pluripotent cells. 


\section{Routes used for cell therapy}

There are four routes by which cells can be delivered to patients with disease of or damage to the central nervous system (CNS), including the parenchyma of the brain or spinal cord, ${ }^{4-7}$ cerebrospinal fluid (in the ventricle and subarachnoid space), ${ }^{8,9}$ the vasculature ${ }^{10}$ (intravenous or intra-arterial), and the intranasal route, ${ }^{11}$ or a combination of these routes. ${ }^{5,6,12}$

\section{Clinical progress using cell therapy in disease and injury}

Olfactory ensheathing cells, umbilical cord stromal cells, Schwann cells, neural progenitor cells, bone marrow stromal cells, and umbilical cord blood mononuclear cells have been tested in the clinic. Thousands of patients with CNS disorders have received a variety of cell treatments, and the majority have successfully achieved a degree of functional neurological restoration along with improvement in quality of life. ${ }^{13}$ Herein, we briefly summarize some of the more important achievements.

Patients with complete chronic spinal cord injury have been shown to achieve clinical neurorestoration to some degree by cell therapies, and should no longer be told that nothing can be done. ${ }^{14}$ In those review papers, patients showed improvement in their grades or scores for motor and sensory function according to the American Spinal Injury Association assessment standard or improved their ability to perform activities of daily living on the International Association of Neurorestoratology Spinal Cord Injury Functional Rating Scale.

Cell therapies for patients with stroke in the acute or chronic phase have demonstrated efficacy in terms of improved neurological outcome and quality of life., ${ }^{5,15}$ For example, patients showed functional amelioration of speech, muscle strength, balance, and pain.

Cell therapies have been shown to stabilize or improve neurological functioning and quality of life in patients with amyotrophic lateral sclerosis to some extent for a period of time according to the Amyotrophic Lateral Sclerosis Functional Rating Scale assessment standard. ${ }^{16-18}$

Farge et al ${ }^{19}$ reported that autologous hematopoietic stem cell transplantation is capable of inducing sustained remissions for more than 5 years in patients with severe autoimmune diseases, in particular those with multiple sclerosis, with similar results being shown in other studies. ${ }^{13,20-25}$ Although not providing a cure, such therapy may lead to prolonged disease stabilization and attenuate the aggressive course of multiple sclerosis. ${ }^{26}$
Children with cerebral palsy can derive benefit from cell therapy, including improved motor function on the GMFM66 and Care Questionnaire Scale. ${ }^{27-29}$ Degenerative diseases, such as Alzheimer's disease ${ }^{30-32}$ and Parkinson's disease, have shown a good response to cell therapy, ${ }^{33-35}$ for example, reliving patients' stiffness and walking ability. Traumatic brain injury ${ }^{36}$ and other CNS diseases and damage can also benefit from cell therapy. ${ }^{13}$

\section{Neurorestorative mechanisms of cell therapy}

Generally, cell therapy has been demonstrated to have a neuroprotective effect, supporting axonal regeneration, remyelination of demyelinated axons, neuroplasticity, neuromodulation, neurogenesis, angiogenesis, and the anti-inflammatory response (eg, moderating activation of astrocytes), as well as reducing scar/cavity formation and having strong phagocytic activity. ${ }^{1,3,37,38}$ The main mechanism of neurorestoration by cell therapy may not be cell replacement as previously thought, but instead involve a neuroprotective effect via immunomodulatory substances and neurotrophic growth factors. ${ }^{39}$

\section{Misconceptions about clinical cell therapy}

There are some misconceptions regarding cell therapy, which are a major obstacle to the development of neurorestoratology and its therapeutic use in patients with neurologica diseases and injury. Correcting these misunderstandings is a major challenge facing cell therapy.

\section{Overuse or misuse of the term "stem cell”}

Mononuclear cells from bone marrow, cord blood, and peripheral blood broadly include monocytes/macrophages, lymphocytes, and a small amount of stem cells. Unfortunately, many scientists and physicians use terms 'stem cell' to replace 'mononuclear cell' in their published papers. After expanding mononuclear cells in culture, even stem cells increase in number, but most of them are a homogenous mix of cell. Cells that are cultured and expanded from umbilical cord or adipose tissue are also a homogenous mix of cells. Up until now, these cells cannot be identified by special markers as purely "stem cells". More commonly now, they are known as stromal cells. ${ }^{40}$ These cells would be more correctly described as "stromal" or "mononuclear" cells. 


\section{Misunderstandings about cell safety}

Immature or mature functional cells and mesenchymal or stromal cells have been shown to be safe and without too many problems in numerous experimental and clinical studies; however, the tumorigenicity of totipotent or pluripotent stem cells remains a safety issue. Thus, their investigation in clinical trials remains limited until researchers find a way of minimizing the risk of tumorigenicity, even though these cells have demonstrated benefit in the treatment of disease and repair of damage in experimental studies. ${ }^{41-46}$ The biggest misunderstanding is to take the issue of totipotent or pluripotent stem cell as the issue of whole cell therapy.

\section{Misconceptions about the mechanisms of neurorestoration}

Paying too much attention to structural neuroregeneration is a mistake. There are many alternative mechanisms for currently achievable functional neurorestoration. Many people erroneously believe that neuroregeneration will bring about neurological functional recovery or neuroregeneration must mean functional neurological recovery. In fact, neurorestoration means neurological functional recovery, regardless of what mechanisms are involved, and is a more accurate term than neuroregeneration when attempting to clarify the real implications of functional recovery.

\section{Confusion about ethical issues}

The ethics of neurorestorative cell therapy are complicated. It is currently believed that new clinical trials or experimental treatments should not be embarked upon until they have been approved by a scientific body and ethics committee.$^{47}$ Patients (or their representatives) should sign a consent document that informs them of the potential benefits and risks of the study treatment. These are the core ethical issues to which attention should be paid. Unfortunately, there is some confusion with regard to political, legal, and religious issues versus ethical issues. From the standpoint of the Declaration of Helsinki, ${ }^{48}$ there are no ethical problems with clinical cell therapy, and intending to discuss ethical issues about cell therapy is just a pseudo-proposition. Preventing its use in the treatment of patients is the real ethical issue, given that cell therapy has been shown to be able to restore some neurological function and improve quality of life for many patients. Furthermore, if patients are denied cell-based neurorestorative treatment for ethical reasons, they may miss the opportunity to improve their neurological function and quality of life.

\section{Misunderstanding of effects}

Patients with severe spinal cord injury, traumatic brain injury, or a progressive CNS degenerative disorder often believe that they could be cured almost immediately by cell therapy as a result of deliberate exaggerations by certain companies and overstatement of the curative properties of stem cells in the media. So their dream of a cure makes them have higher expectations. These unrealistic hopes of a cure have diverted people away from the medical treatments already available and led to them neglecting the functional recovery that can be achieved using current neurorestorative strategies. All specialists in this field know that progress is difficult to achieve, but a little improvement is better than none, given that small functional gains may be extremely important for a patient's survival and well-being. On the other hand, many patients, along with some scientists and physicians, believe that there are currently no known therapeutic methods to restore neurological function, even partially. ${ }^{49}$ To counteract those misconceptions, patients with CNS lesions should be encouraged to recognize the benefits of the practical neurorestoration techniques that are already available.

\section{Legislative challenges and application of standards in cell therapy}

Cell therapy should be the main strategy for neurorestoration in the 21 st century. Until now, there have been no uniform laws or regulatory channels for cell therapy that are accepted in all countries, and controversy persists regarding the use of cell therapy as a medicine or a treatment technique. Further, few application standards or guidelines have been published by international professional associations. ${ }^{50}$ Therefore, it is a challenge for any government to introduce legislation or provide regulatory guidance for clinical implementation of cell therapy. Professional associations attempting to devise reasonable and practicable application standards or guidelines for clinical practice face similarly complex issues.

Physicians and scientists should try their best to help patients through translational medicine by taking action, not just talking. They also need to undertake further research regarding optimal cell combinations, the best route for cell delivery, the most suitable cell dosage, the best treatment for patients with specific conditions, the best time windows for treatment or repeat treatment, the most suitable types of cell for different diseases or injuries, and the best type of cell therapy to use in combination with other neurorestorative strategies or 
optimal cell-based comprehensive neurorestorative therapies. If these issues are addressed, patients will have an opportunity to improve their quality of life further.

In summary, it is less controversy that cell therapy have been able to restore some neurological functions. However, there are some misunderstandings that are hindering the development of neurorestoratology and depriving patients of the benefits of this valuable treatment. Dispelling these misconceptions is an important task ahead, both for the discipline and for patients. Introducing legislation at the government level and development of application standards by professional associations will allow this therapy to develop in a correct direction.

\section{Disclosure}

The authors report no conflicts of interest in this work.

\section{References}

1. Huang H, Chen L, Sanberg P. Cell therapy from bench to bedside translation in CNS neurorestoratology era. Cell Med. 2010;1: $15-46$.

2. Janowski M, Date I. Systemic neurotransplantation - a problem-oriented systematic review. Rev Neurosci. 2009;20:39-60.

3. Huang H, Chen L, Sanberg P. Clinical achievements, obstacles, falsehoods, and future directions of cell-based neurorestoratology. Cell Transplant. 2012;21 Suppl 1:S3-S11.

4. Huang $\mathrm{H}$, Chen $\mathrm{L}$, Wang $\mathrm{H}$, et al. Influence of patients' age on functional recovery after transplantation of olfactory ensheathing cells into injured spinal cord injury. Chin Med J (Engl). 2003;116:1488-1491.

5. Chen L, Xi H, Huang H, et al. Multiple cell transplantation based on an intraparenchymal approach for patients with chronic phase stroke. Cell Transplant. 2013;22 Suppl 1:S83-S91.

6. Xi H, Chen L, Huang H, et al. Preliminary report of multiple cell therapy for patients with multiple system atrophy. Cell Transplant. 2013; 22 Suppl 1:S93-S99.

7. Paul C, Samdani AF, Betz RR, Fischer I, Neuhuber B. Grafting of human bone marrow stromal cells into spinal cord injury: a comparison of delivery methods. Spine (Phila Pa 1976). 2009;34: 328-334.

8. Callera F, de Melo CM. Magnetic resonance tracking of magnetically labeled autologous bone marrow CD34+ cells transplanted into the spinal cord via lumbar puncture technique in patients with chronic spinal cord injury: CD34+ cells' migration into the injured site. Stem Cells Dev. 2007;16:461-466.

9. Kumar AA, Kumar SR, Narayanan R, Arul K, Baskaran M. Autologous bone marrow derived mononuclear cell therapy for spinal cord injury: a phase I/II clinical safety and primary efficacy data. Exp Clin Transplant. 2009;7:241-248.

10. Cristante AF, Barros-Filho TE, Tatsui N, et al. Stem cells in the treatment of chronic spinal cord injury: evaluation of somatosensitive evoked potentials in 39 patients. Spinal Cord. 2009;47:733-738.

11. Danielyan L, Schafer R, von Ameln-Mayerhofer A, et al. Intranasal delivery of cells to the brain. Eur J Cell Biol. 2009;88:315-324.

12. Moviglia GA, Varela G, Brizuela JA, et al. Case report on the clinical results of a combined cellular therapy for chronic spinal cord injured patients. Spinal Cord. 2009;47:499-503.

13. Huang H, Chen L, Xi H, et al. [Olfactory ensheathing cells transplantation for central nervous system diseases in 1,255 patients]. Zhongguo Xiu Fu Chong Jian Wai Ke Za Zhi. 2009;23:14-20. Chinese.
14. Huang H, T Sun T, Chen L, et al. Consensus of clinical neurorestorative progresses in patients with complete chronic spinal cord injury. Cell Transplant. October 9, 2014. [Epub ahead of print.]

15. Qiao L,Lu J, Huang H. Clinical neurorestorative progress in stroke. Journal of Neurorestoratology. 2014, in press.

16. Huang H, Chen L, Xi H, et al. Fetal olfactory ensheathing cells transplantation in amyotrophic lateral sclerosis patients: a controlled pilot study. Clin Transplant. 2008;22:710-718.

17. Chen L, Chen D, Xi H, et al. Olfactory ensheathing cell neurorestorotherapy for amyotrophic lateral sclerosis patients: benefits from multiple transplantations. Cell Transplant. 2012;21 Suppl 1:S65-S77.

18. Chen L, Huang H, Xi H, Mao G. Clinical neurorestorative progress in amyotrophic lateral sclerosis. Journal of Neurorestoratology. 2014, in press.

19. Farge D, Labopin M, Tyndall A, et al. Autologous hematopoietic stem cell transplantation for autoimmune diseases: an observational study on 12 years' experience from the European Group for Blood and Marrow Transplantation Working Party on Autoimmune Diseases. Haematologica. 2010;95:284-292.

20. Burt RK, Loh Y, Cohen B, et al. Autologous non-myeloablative haemopoietic stem cell transplantation in relapsing-remitting multiple sclerosis: a phase I/II study. Lancet Neurol. 2009;8:244-253.

21. Fassas A, Passweg JR, Anagnostopoulos A, et al; Autoimmune Disease Working Party of the EBMT (European Group for Blood and Marrow Transplantation). Hematopoietic stem cell transplantation for multiple sclerosis. A retrospective multicenter study. J Neurol. 2002;249: 1088-1097.

22. Mehta T, Feroz A, Thakkar U, Vanikar A, Shah V, Trivedi H. Subarachnoid placement of stem cells in neurological disorders. Transplant Proc. 2008;40:1145-1147.

23. Saiz, A, Blanco Y, Berenguer J, et al. [Clinical outcome 6 years after autologous hematopoietic stem cell transplantation in multiple sclerosis]. Neurologia. 2008;23:405-407. Spanish.

24. Xu J, Ji BX, Su L, et al. Clinical outcome of autologous peripheral blood stem cell transplantation in opticospinal and conventional forms of secondary progressive multiple sclerosis in a Chinese population. Ann Hematol. 2011;90:343-348.

25. Yamout B, Hourani R, Salti H, et al. Bone marrow mesenchymal stem cell transplantation in patients with multiple sclerosis: a pilot study. Neuroimmunology. 2010;227:185-189.

26. Geng TC, Mark V. Clinical neurorestorative progress in multiple sclerosis. Journal of Neurorestoratology. 2014, in press.

27. Chen L, Huang H, Xi H, et al. Intracranial transplant of olfactory ensheathing cells in children and adolescents with cerebral palsy: a randomized controlled clinical trial. Cell Transplant. 2010;9:185-191.

28. Luan Z, Liu W, Qu S, et al. Effects of neural progenitor cell transplantation in children with severe cerebral palsy. Cell Transplant. 2012; 21 Suppl 1:S91-S98.

29. Sharma A, Gokulchandran N, Chopra G, et al. Administration of autologous bone marrow derived mononuclear cells in children with incurable neurological disorders and injury is safe and improves their quality of life. Cell Transplant. 2012;21 Suppl 1:S1-S12.

30. Sanchez-Ramos J, Cimino C, Avila R, et al. Pilot study of granulocyte-colony stimulating factor for treatment of Alzheimer's disease. J Alzheimers Dis. 2012;31:843-855.

31. Qiao L, Huang H, Muresanu DF. Clinical neurorestorative progress in Alzheimer's disease. Journal of Neurorestoratology. 2014;5:1-9.

32. Seo SW, Lee JI, Kim CH, et al. A phase I trial of parenchymal injection of umbilical cord stem cells in Alzheimer's disease. Alzheimers Dement. 2013;9(4 Suppl):291.

33. Ma Y, Tang C, Chaly T, et al. Dopamine cell implantation in Parkinson's disease: long-term clinical and (18)F-FDOPA PET outcomes. $J$ Nucl Med. 2010;51:7-15.

34. Kefalopoulou Z, Politis M, Piccini P, et al. Long-term clinical outcome of fetal cell transplantation for Parkinson disease: two case reports. JAMA Neurol. 2014;71:83-87. 
35. Chen L, et al. Clinical neurorestorative progress in Parkinson disease. Journal of Neurorestoratology. 2014, in press.

36. Huang $\mathrm{H}$, Chen L, Huang $\mathrm{H}$. Clinical neurorestorative progress in traumatic brain injury. Journal of Neurorestoratology. In press 2015.

37. Hale DM, Ray S, Leung JY, et al. Olfactory ensheathing cells moderate nuclear factor kappaB translocation in astrocytes. Mol Cell Neurosci. 2011;46:213-221.

38. Ziegler MD, Hsu D, Takeoka A, et al. Further evidence of olfactory ensheathing glia facilitating axonal regeneration after a complete spinal cord transection. Exp Neurol. 2011;229:109-119.

39. De Feo D, Merlini A, Laterza C, Martino G. Neural stem cell transplantation in central nervous system disorders: from cell replacement to neuroprotection. Curr Opin Neurol. 2012;25:322-333.

40. Salem HK, Thiemermann C. Mesenchymal stromal cells: current understanding and clinical status. Stem Cells. 2010;28:585-596.

41. Chen LW, Kuang F, Wei LC, et al. Potential application of induced pluripotent stem cells in cell replacement therapy for Parkinson's disease. CNS Neurol Disord Drug Targets. 2011;10:449-458.

42. El-Amraoui A, Petit C. Stem cell therapy in the inner ear: recent achievements and prospects. Med Sci (Paris). 2010;26:981-985.

43. Hernándeza J, Torres-Espína A, Navarro X. Adult stem cell transplants for spinal cord injury repair: current state in preclinical research. Curr Stem Cell Res Ther. 2011;6:273-287.

44. Hunt CJ. Cryopreservation of human stem cells for clinical application: a review. Transfus Med Hemother. 2011;38:107-123.
45. Sendtner M. Therapy development in spinal muscular atrophy. Nat Neurosci. 2010;13:795-799.

46. Tomaskovic-Crook E, Crook JM. Human embryonic stem cell therapies for neurodegenerative diseases. CNS Neurol Disord Drug Targets. 2011;10:440-448.

47. Borlongan CV, McWhirter C, Fultz-Carver C, Fitzgerald KT, Sanberg PR. The case for an ethics research consortium for emerging technologies: public perception of stem cell research and development. Technol Innov. 2010;12:21-28.

48. World Medical Association General Assembly. WMA Declaration of Helsinki - Ethical Principles for Medical Research Involving Human Subjects. Available from: http://www.wma.net/en/30publications/10policies/ b3/index.html. Accessed December 19, 2014.

49. Anderberg L, Aldskogius H, Holtz A. Spinal cord injury - scientific challenges for the unknown future. Ups J Med Sci. 2007;112: 259-288.

50. Chinese Branch of International Association of Neurorestoratology (IANR); Preparatory Committee of Chinese Association of Neurorestoratology. Standard recommendations for the application of Chinese clinical cell therapy for neurorestoration (2012). Cell Transplant. 2013;22 Suppl 1:S5-S10.
Journal of Neurorestoratology

\section{Publish your work in this journal}

The Journal of Neurorestoratology is an international, peer-reviewed, open access online journal publishing original research and review articles on the subject of Neurorestoratology. To provide complete coverage of this revolutionary field the Journal of Neurorestoratology will report on relevant experimental research, technological advances, and

\section{Dovepress}

clinical achievements. The manuscript management system is completely online and includes a very quick and fair peer-review system, which is all easy to use. Visit http://www.dovepress.com/testimonials.php to read real quotes from published authors.

Submit your manuscript here: http://www.dovepress.com/journal-of-neurorestoratology-journal 